\title{
Hyperventilation, central autonomic control, and colonic tone in humans
}

\author{
M J Ford, M J Camilleri, R B Hanson, J A Wiste, M J Joyner
}

\begin{abstract}
Symptoms attributable to hyperventilation are common among patients with the irritable bowel syndrome (IBS); indeed, some have suggested that hyperventilation may exacerbate the alimentary symptoms of IBS. Hyperventilation changes haemodynamic function through central and peripheral mechanisms; its effects on colonic motor function, however, are unknown. The aim of this study, therefore, was to assess the effects of hyperventilation on colonic tone and motility and on cardiovascular autonomic activity, and to discover if hypocapnia was critical to elicit the response. Phasic and tonic motility of the transverse and sigmoid colon, end tidal $\mathrm{PCO}_{2}$, pulse rate, and beat to beat pulse variability were assessed before, during, and after a five minute period of hypocapnic hyperventilation in 15 healthy volunteers; in seven other subjects, effects of both eucapnic and hypocapnic hyperventilation were evaluated. Hypocapnic but not eucapnic hyperventilation produced an increase in colonic tone and phasic contractility in the transverse and sigmoid regions and an increase in pulse rate and pulse interval variability. The findings are consistent with inhibition of sympathetic innervation to the colon or direct effects of hypocapnia on colonic smooth muscle, or both. These physiological gut responses suggest that some of the changes in colonic function are caused by altered brain or autonomic control mechanisms.

(Gut 1995; 37: 499-504)
\end{abstract}

Keywords: colon motility, irritable bowel syndrome, hyperventilation.

Hyperventilation produces a rise in heart rate, cardiac output, and forearm blood flow and a fall in peripheral vascular resistance attributable respectively to vasodilatation and venoconstriction. ${ }^{1}$ Hyperventilation is, however, a potent modulator of central autonomic outflow attributable to 'central command' effects - that is, reflex brainstem responses - and to hypocapnic effects on the hypothalamus, hippocampus, limbic system, and locus ceruleus resulting in decreased central parasympathetic and sympathetic outflow. ${ }^{2-7}$ In patients with the irritable bowel syndrome (IBS), non-alimentary symptoms are frequently encountered, including those symptoms conventionally associated with the hyperventilation syndrome such as palpitations, dizziness, and paresthesiae. ${ }^{7-10}$
Physical, mental, and emotional stressors have been well shown to induce changes in oesophageal, gastric, small intestinal, and colonic motility in both healthy subjects and patients with IBS. ${ }^{11}$ Acute stress, however, bears little resemblance to the chronic distress induced by life events and difficulties and many patients do not associate changes in symptom levels with changes in stress patterns. Other phenomena, such as hyperventilation, may mediate changes in states of arousal and hence central autonomic outflow. It is possible that such changes could not only influence colonic motor function but, by changing tone and motility, change the set point at which tension receptors are stimulated, and so determine sensory function and visceral sensitivity.

Animal studies have shown the existence of a functional subset of sympathetic neurons that regulate gut motility; some of these neurons are inhibited by respiratory stimulation. ${ }^{1213}$ Furthermore, studies in humans have shown that hyperventilation increases oesophageal and gastric antral contractility ${ }^{14}{ }^{15}$; colonic motility, however, has not previously been shown to change in response to hyperventilation. ${ }^{16}$ Given the association of IBS with the hyperventilation syndrome ${ }^{8-10}$ and changed autonomic function in some IBS patients, ${ }^{17-19}$ we wished to test the hypothesis that hyperventilation induces significant changes in colonic motor function, which are mediated by the autonomic nervous system. Our aims were firstly, to evaluate proximal and distal colonic tone and phasic motility together with autonomic cardiovascular responses to hypocapnic hyperventilation in conscious, healthy human volunteers and secondly, to discover if hypocapnia was critical in eliciting this response.

\section{Methods}

\section{HEALTHY VOLUNTEERS}

Twenty two healthy volunteers, aged 19-62 years (mean (SEM) $31(2 \cdot 1) ; 12 \mathrm{M}$ and $10 \mathrm{~F}$ ), were recruited by public advertisement. None had had previous gastrointestinal surgery; IBS, anxiety, and depressive disorders were excluded using validated, screening questionnaires, ${ }^{2021}$ a clinical interview, and physical examination. The studies were approved by Mayo Clinic's Institutional Review Board.

\section{COLONIC MOTOR FUNCTION}

A multilumen, combined manometric and barostat assembly was placed in the prepared colon with the aid of colonoscopy and fluoroscopy. ${ }^{22} 23$ Tonic and phasic contractile
Correspondence to: Gastroenterology Research Unit, Mayo Clinic, Rochester, MN 55905, USA Accepted for publication 16 February 1995 
activity of the colon were measured by barostat balloons and conventional manometry respectively. The combined assembly comprised six manometric ports, one $10 \mathrm{~cm}$ orad to a $10 \mathrm{~cm}$ polythene balloon positioned in the transverse colon, one $10 \mathrm{~cm}$ aborad to a similar balloon in the sigmoid colon and four ports, $10 \mathrm{~cm}$ apart, between the two balloons, which were $50 \mathrm{~cm}$ apart. Each balloon was linked to a barostat and an electromechanical air injection device. The barostat balloons were inflated to a minimum distending pressure, defined as the pressure (and volume) at which respiratory excursions were regularly recorded as changes in the barostat volume. The 'operating pressure' was set $2 \mathrm{~mm} \mathrm{Hg}$ above the minimum distending pressure (median pressure $10 \mathrm{~mm} \mathrm{Hg}$, range $8-14 \mathrm{~mm}$ $\mathrm{Hg}$ ). Intraballoon volumes and manometric pressure changes in response to contractile activity were monitored continuously throughout the study. The technique and its use in healthy and clinical states has previously been shown to be both safe and effective when combined with manometry. ${ }^{22} 23$

\section{HYPERVENTILATION AND HAEMODYNAMIC}

FUNCTION

The methodology of voluntary hyperventilation was similar to that extensively used in previous pathophysiological studies. ${ }^{24-26}$ In the absence of pulmonary disease, the end tidal $\mathrm{PCO}_{2}\left(\mathbf{P}_{\mathrm{et}} \mathrm{CO}_{2}\right)$ provides an accurate breath by breath estimate of the arterial $\mathrm{PCO}_{2} \cdot{ }^{26}$ The $\mathrm{P}_{\mathrm{et}} \mathrm{CO}_{2}$ was measured continuously throughout the study using a nasal airflow sensor and standard capnography $\left(\mathrm{CO}_{2} \mathrm{SMO}\right.$, Novametrix Medical Systems, Wallingford, CT). Subjects were asked to hyperventilate at 30 breaths per minute, using a mouthpiece and metronome, so that $\mathrm{P}_{\mathrm{et}} \mathrm{CO}_{2}$ was maintained at less than 26 $\mathrm{mm} \mathrm{Hg}$ for five minutes. Colonic tone and phasic contractility were assessed over four five minute periods before, during, and for two periods after the test period of hyperventilation. The arterial pulse rate was monitored continuously using conventional digital pulse plethysmography $\left(\mathrm{CO}_{2} \mathrm{SMO}\right.$, Novametrix Medical Systems, Wallingford, CT). After demonstrating the effects of hyperventilation in the first 15 subjects, an addendum to the protocol was written to consider whether hypocapnia was critical to the elicitation of the response to hyperventilation. Thus, in seven subjects, eucapnic hyperventilation was also performed for a five minute period, 15 minutes before hypocapnic hyperventilation. Subjects were instructed to hyperventilate at 30 breaths per minute during which they remained unaware that $\mathrm{P}_{\mathrm{et}} \mathrm{CO}_{2}$ values were being held constant by the addition of $1-21 / \mathrm{min}$ of carbon dioxide to the inlet of the mouthpiece. The order of eucapnic, followed by hypocapnic, hyperventilation was not randomised to avoid any possible carry over effects of hypocapnia. Moreover, we measured all parameters for five minutes before each hyperventilation period to ensure that the baseline recordings were similar before the two perturbations.

\section{EXPERIMENTAL DESIGN}

All subjects were admitted to the General Clinical Research Center at St Mary's Hospital for bowel preparation comprising 1.5-2 1 oral colonic lavage solution (polyethylene glycol and electrolyte solution) on the evening before the study. All gave written informed consent and women of childbearing potential had a negative plasma $\beta$-human chorionic gonadotrophin pregnancy test. After an overnight fast, colonoscopy was performed under conscious sedation with intravenous midazolam $(0.07$ $\mathrm{mg} / \mathrm{kg}$ ); sedation was reversed immediately after the procedure with intravenous flumazenil $(0 \cdot 2-0.5 \mathrm{mg})$ to ensure return to full consciousness. No endoscopic abnormalities were seen and the combined manometry and balloon assembly was introduced into the colon over a guidewire and positioned under fluoroscopic control. After 60 minutes' observation, the experiment was started with continuous monitoring of colonic tone and motility, $\mathrm{P}_{\mathrm{et}} \mathrm{CO}_{2}$ and digital pulse plethysmography as described above.

\section{DATA ANALYSIS}

\section{Colonic motor parameters}

Phasic manometric pressure activity and changes in both pressure and volume of the two barostat balloons were sampled as analogue signals at $8 \mathrm{~Hz}$ and converted to digital signals before entry into a computer. As in previous studies, movement and respiratory artefacts were filtered out using a modified VAX LAB filtering program (Digital Equipment Corporation, Boston, MA) to remove waveforms with a frequency of greater than 10 per minute, pressure changes of less than 10 $\mathrm{mm} \mathrm{Hg}$ amplitude or less than four seconds duration. ${ }^{22}{ }^{23}$ Phasic pressure activity measured manometrically was expressed as the activity index - that is, the area under the contraction curve per five minute period. The mean manometric phasic activity in the transverse and sigmoid colon was calculated from the mean values recorded from two sensors positioned proximal and distal to the barostat balloons. The barostat balloon volumes recorded in the transverse and sigmoid colon were similarly computer analysed to separate baseline balloon volume from phasic volume events. Phasic volume events were defined as changes in volume greater than $10 \%$ of baseline volume and occurring at a frequency of one to four per minute. Baseline volumes were calculated by computerised exclusion of the phasic volume events from the barostat recordings and averaged over 60 second time frames during each five minute period to represent colonic tone.

\section{Haemodynamic and respiratory parameters}

For each 30 second time frame of the 20 minute study, mean pulse rates, respiratory rates, and end tidal $\mathbf{P}_{\mathrm{et}} \mathrm{CO}_{2}$ values were calculated; similarly, mean beat to beat pulse intervals were calculated using a modification of the VAX LAB peak finding program. To 
TABLE I Effect of hypocapnic hyperventilation on regional colonic tone, end tidal $\mathrm{PCO}_{2}$ pulse rate, and pulse interval variability $(n=22$, mean (SEM))

\begin{tabular}{|c|c|c|c|c|}
\hline & Before & $H V T$ & $\begin{array}{l}\text { After first } \\
\text { time period }\end{array}$ & $\begin{array}{l}\text { After second } \\
\text { time period }\end{array}$ \\
\hline $\begin{array}{l}\text { Tone } \\
\text { Baseline barostat volume in } \\
\text { TC (ml) } \\
\text { Mean \% change in TC tone }\end{array}$ & $146 \cdot 3(10)$ & $\begin{array}{r}131 \cdot 4(10) \\
10 \cdot 3(2 \cdot 1) \dagger\end{array}$ & $\begin{array}{l}134(9) \\
7 \cdot 8(2 \cdot 3) \dagger\end{array}$ & $\begin{array}{c}143(10) \\
2(3)\end{array}$ \\
\hline $\begin{array}{l}\text { Baseline barostat volume in } \\
\text { SC }(\mathrm{ml}) \\
\text { Mean } \% \text { change in SC tone* }\end{array}$ & $118(9) \ddagger$ & $\begin{array}{l}109(8) \\
6.5(1.4) \dagger\end{array}$ & $\begin{array}{l}107(6) \\
7 \cdot 4(1 \cdot 8) \dagger\end{array}$ & $\begin{array}{l}115(8) \\
1.6(1 \cdot 3)\end{array}$ \\
\hline $\begin{array}{l}\text { Motility } \\
\text { TC phasic activity index } \\
\text { (AUC mm Hg/5 min) } \\
\text { SC phasic activity index } \\
\text { (AUC } \mathrm{mm} \mathrm{Hg} / 5 \mathrm{~min} \text { ) }\end{array}$ & $202(54)$ & $153(36)$ & $361(69) \dagger$ & $205(51)$ \\
\hline $\begin{array}{l}\text { Others } \\
\text { End tidal } \mathrm{PCO}_{2}(\mathrm{~mm} \mathrm{Hg}) \\
\text { Pulse rate }(\text { per min }) \\
\text { Coefficient of variation of } \\
\text { pulse interval }(\%)\end{array}$ & $\begin{array}{l}41 \cdot 8(0 \cdot 7) \\
65 \cdot 2(1 \cdot 8) \\
16 \cdot 9(1 \cdot 6)\end{array}$ & $\begin{array}{l}23 \cdot 5(0 \cdot 6) \dagger \\
81 \cdot 2(1 \cdot 8) \dagger \\
36 \cdot 8(4 \cdot 5) \dagger\end{array}$ & $\begin{array}{l}31 \cdot 6(0 \cdot 8) \dagger \\
65 \cdot 7(1 \cdot 8) \\
29 \cdot 3(5 \cdot 2) \dagger\end{array}$ & $\begin{array}{l}38.9(0.8) \\
61.5(1.9) \\
14 \cdot 2(1.4)\end{array}$ \\
\hline
\end{tabular}

$\mathrm{HVT}=$ hyperventilation; * relative to pre-hyperventilation; $\mathrm{TC}=$ transverse colon; $\mathrm{SC}=$ sigmoid colon; AUC $=$ area under curve.

$\dagger \mathrm{p}<0.01 v$ pre-hyperventilation by paired analysis; $\ddagger \mathrm{p}<0.05 v$ transverse colon.

obtain a dynamic measure of cardiovascular autonomic activity, the coefficient of variation of the pulse interval per minute (standard deviation/mean pulse peak interval) was calculated. Thus, an increase in the coefficient of variation in pulse interval implies increased parasympathetic activity or decreased sympathetic activity, or both. ${ }^{27}$

\section{Statistical analysis}

Effects of hypocapnic hyperventilation were assessed on the entire group of 22 healthy subjects. The five minute period before hyperventilation and the next three five minute periods were compared by paired $t$ tests for normally distributed data, that is colonic tone (baseline balloon volume), end tidal $\mathrm{PCO}_{2}$ value, and pulse rate. For data that were not normally distributed - that is, colonic phasic activity and the coefficient of variation of the pulse interval - we used the non-parametric paired Wilcoxon rank sum tests. In view of the performance of pairwise comparisons of data during hyperventilation and post-hyperventilation periods with the pre-hyperventilation period, we applied Bonferroni's correction for multiple tests $(p<0.05+3)$, and thus $p<0.017$ rather than $p<0.05$ was considered significant.

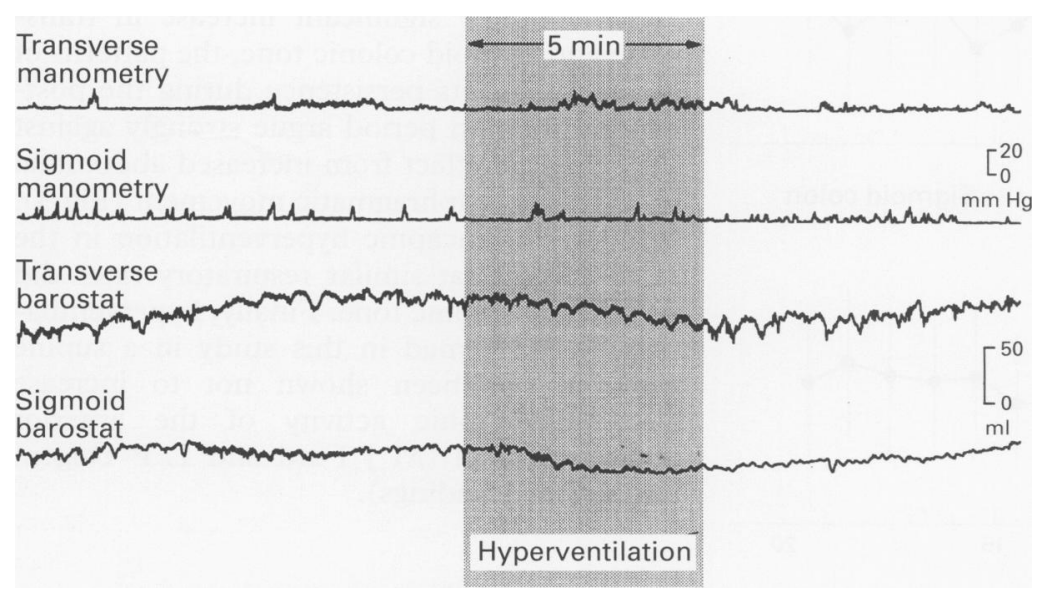

Figure 1: A typical recording of the effects of hypocapnic hyperventilation (shaded area) on phasic and tonic contractility in the transverse and sigmoid colon. Increases in colonic tone are reflected by decreases in baseline barostat volume.
In the eucapnic hyperventilation experiment, two pairwise comparisons with the prehyperventilation period were performed, Bonferroni's correction was again applied, and $\mathrm{p}<0.025(\mathrm{p}<0.05+2)$ was considered significant.

\section{Results}

\section{COLONIC MOTOR FUNCTION}

Baseline barostat balloon volumes in the transverse and sigmoid colon were different (Table I, $\mathrm{p}<0.05$ ) under the conditions of the experiment, where the operating pressure was determined by the intrabag pressure that resulted in recording of respiratory artefact. The mean operating pressures in the two balloons were significantly different $(9 \cdot 8(0 \cdot 3)$ $\mathrm{mm} \mathrm{Hg}$ in transverse, and $11.4(0.5) \mathrm{mm} \mathrm{Hg}$ in sigmoid colon; $p<0.01$ ).

Transverse and sigmoid colonic tone increased during hypocapnic hyperventilation (Figs 1, 2, and 3). This effect persisted during the five minute period after cessation of hyperventilation, at a time when $\mathrm{P}_{\mathrm{et}} \mathrm{CO}_{2}$ was still significantly below baseline (Table I, Fig 4). The mean reductions in barostatic balloon volumes (consistent with increased colonic tone) during hypocapnic hyperventilation were $10.3 \%$ and $6.5 \%$ in the transverse and sigmoid colon respectively (see Table I).

Colonic phasic pressure activity was not significantly changed during hypocapnic hyperventilation (Fig 5). Phasic pressure activity increased, however, immediately after cessation of hypocapnic hyperventilation in both the transverse and sigmoid colon (Fig 5). As anticipated, baseline sigmoid colon motility was greater than that seen in the transverse colon.

It is worth noting that the mean baseline barostat volume during the five minutes before eucapnic and hypocapnic hyperventilation were similar $(167(23) \mathrm{ml}$ and $166(24) \mathrm{ml}$ respectively in the transverse colon, and 106 (11) and 105 (10) $\mathrm{ml}$ respectively in the sigmoid colon). Neither tone or phasic motility was significantly changed by eucapnic hyperventilation in contrast with significant increases in both tone and motility after hypocapnic hyperventilation (Table II).

\section{CARDIOVASCULAR AUTONOMIC FUNCTION}

During hypocapnic hyperventilation, $\mathrm{P}_{\mathrm{et}} \mathrm{CO}_{2}$ was significantly lower than baseline and this persisted for five minutes after cessation of hyperventilation (Table I, Fig 3). During hyperventilation, the mean pulse rate increased over baseline and fell rapidly to normal on cessation of hyperventilation. There was a statistically significant increase in pulse interval variability over baseline in both the five minute periods during and immediately after hypocapnic hyperventilation. This effect was not seen in response to eucapnic hyperventilation (Table II). There was a significant increase in pulse rate, however, during eucapnic hyperventilation (69 (3) bpm) compared with 


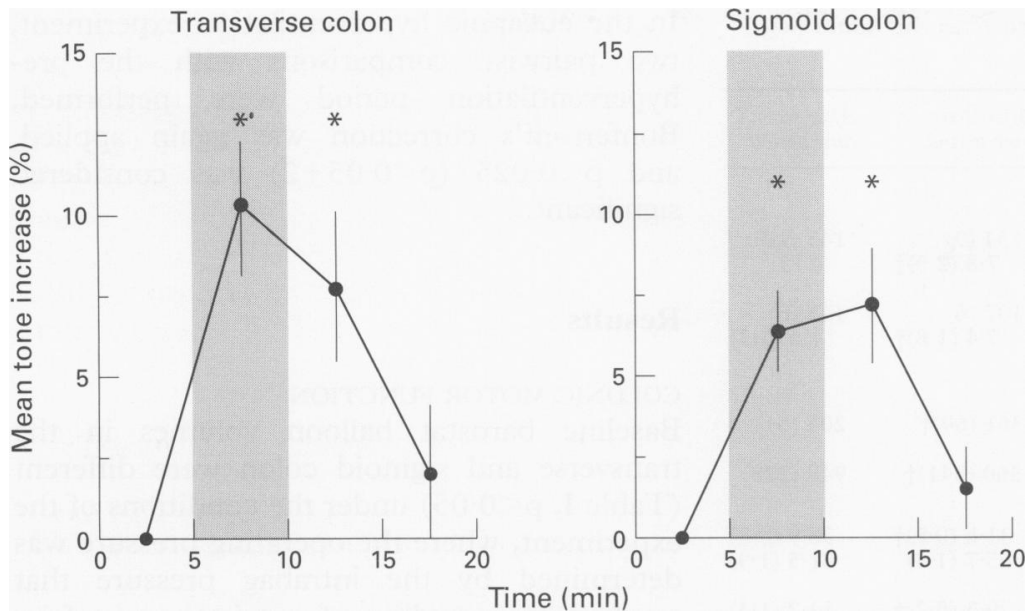

Figure 2: Effect of hypocapnic hyperventilation (shaded area) on baseline barostat volume - that is, colonic tone - in the transverse and sigmoid colon in 22 healthy subjects.

Increased tone, reflected by decreased balloon volumes, are plotted as positive integers. Dato show the mean (SEM) increase in tone (\%). ${ }^{{ }^{*}} p<0.01 \mathrm{v}$ values before the study.

prehyperventilation (63 (3) bpm, $\mathrm{p}=0.01$ by paired analysis).

\section{Discussion}

The physiological responses to hyperventilation are complex. At least three components are recognised in the visceral responses to hyperventilation. Firstly, there is an immediate response attributable to the effects of 'central command' - that is, reflex brainstem responses to real or anticipated muscular effort, causing cardiovagal inhibition, venoconstriction, and a tachycardia with an increase in cardiac output. ${ }^{132829}$ A second component of the hyperventilation response is the decrease in vasoconstriction of the skeletal muscle arteriolar bed resulting in increased limb blood flow. ${ }^{1}$ This is thought to be the result of hypocapnia either acting peripherally or centrally. Peripheral effects of hyperventilation include decreased intracellular calcium ion

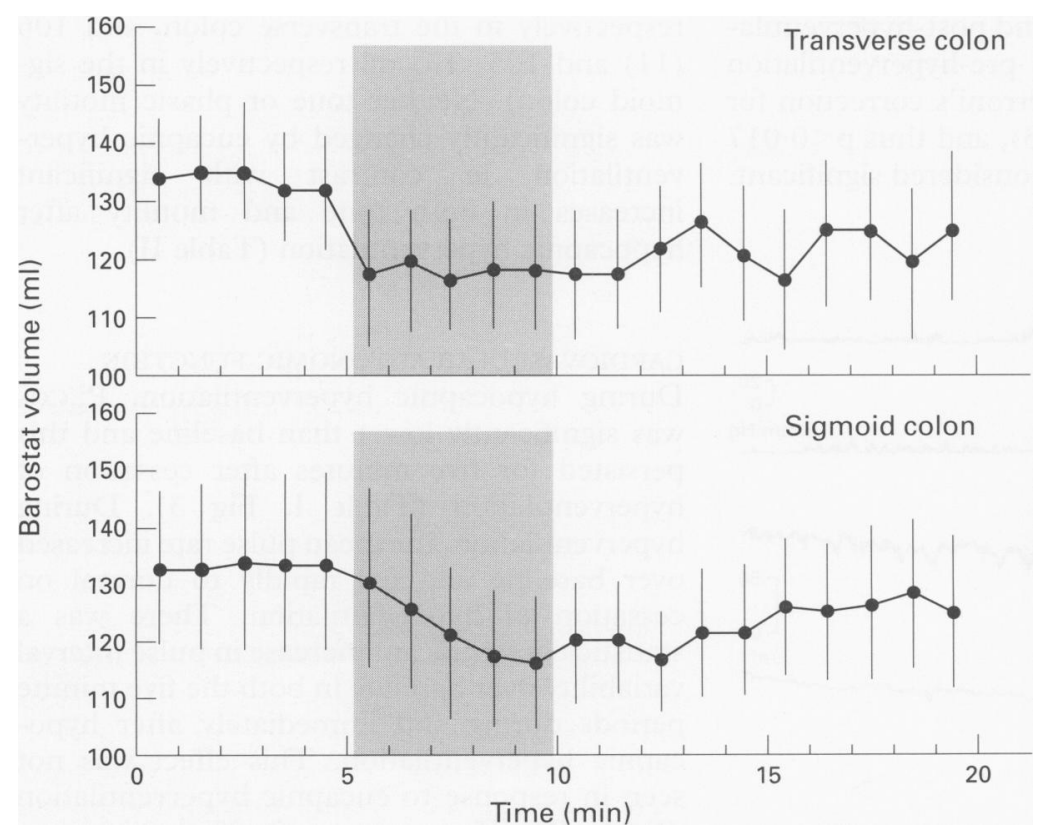

Figure 3: Effect of hypocapnic hyperventilation (shaded area) on mean minute barostat volumes in the transverse and sigmoid colon in 22 healthy subjects. See Fig 2 and Table for summary and statistical analysis. Data shown as mean (SEM).

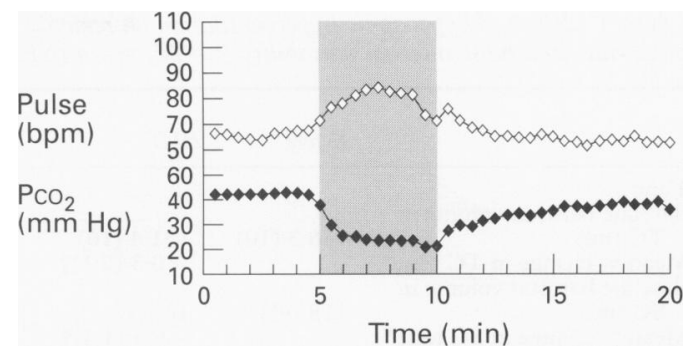

Figure 4: Effect of hypocapnic hyperventilation (shaded area) on pulse rate (bpm) and end tidal $\mathrm{P}_{\mathrm{et}} \mathrm{CO}_{2}$ concentration ( $\mathrm{mm} \mathrm{Hg}$ ) in 22 healthy subjects. See Table I for summary and statistical analysis.

concentration and increased sensitivity to catecholamines resulting in vascular smooth muscle relaxation. ${ }^{13031}$ Central effects of hyperventilation include decreased sympathetic outflow, decreased vasoconstrictor tone in capacitance vessels, ${ }^{1-4,} 3032$ and increasing circulating catecholamine concentrations. ${ }^{33}$ The third component following hyperventilation represents reflex baroreceptor and chemoreceptor homeostatic responses and is characterised by the rapid return of the pulse rate to normal on cessation of hyperventilation consistent with increased cardiovagal activity.

Our findings of hyperventilation induced increases in colonic tone and phasic motility in the transverse and sigmoid colon raise a number of important questions.

Are the effects of hyperventilation on colonic tone significant or artefactual?

The difference in baseline barostat volumes in the transverse and sigmoid colon reflects the greater compliance of the first region rather than the effects of the intraballoon operating pressure as the higher pressures used in the sigmoid would be expected to cause a higher intraballoon volume if the two regions had equal compliance. The increase in colonic tone with hyperventilation might be construed as being clinically insignificant or artefactual as a result of increased abdominal wall tone. However, the data are not consistent with such an analysis. The mean reductions in balloon volumes recorded at the two colonic sites are at least one third the magnitude of the response to a $1000 \mathrm{kcal}$ meal (median volume reduction $25 \%{ }^{34}{ }^{35}$ ). The significant increase in transverse and sigmoid colonic tone, the patterns of its onset, and its persistence during the posthyperventilation period argue strongly against a mechanical effect from increased abdominal wall tone or diaphragmatic movement (Fig 3). In addition, eucapnic hyperventilation in the same subjects at similar respiratory rates did not change colonic tone. Finally, hyperventilation, as performed in this study in a supine position, has been shown not to increase electromyographic activity of the anterior abdominal wall (M J Ford and L P Degen, unpublished findings).

Are the effects of hyperventilation related to hypocapnia?

The phenomenon of a progressive increase in 


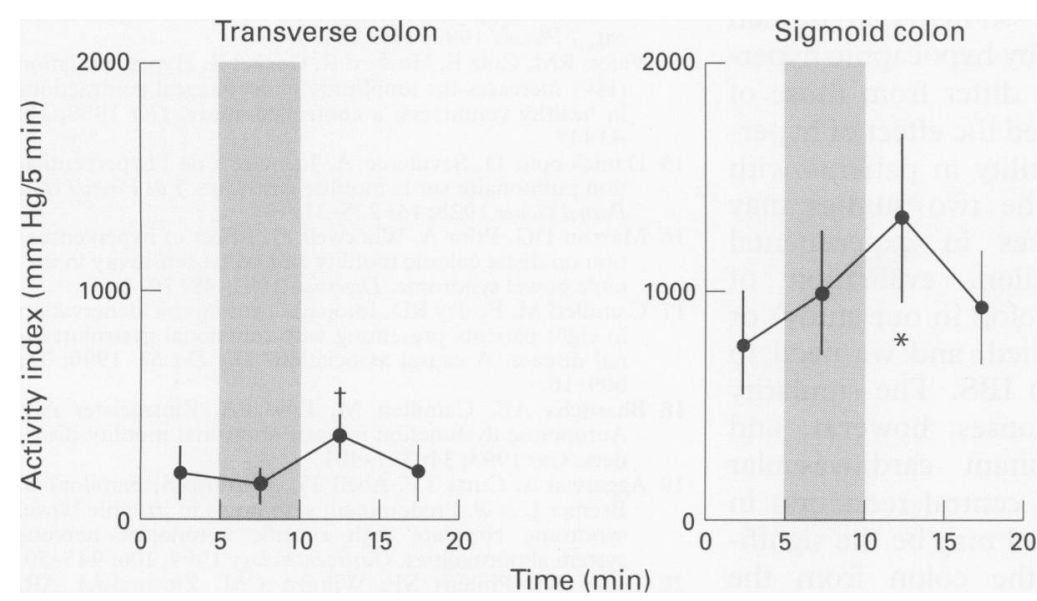

Figure 5: Effect of hypocapnic hyperventilation (shaded area) on phasic contractility in the transverse and sigmoid colon in 22 healthy subjects. Phasic contractility is expressed as the area under the contraction curve (AUC) relative to the prehyperventilation period. Data show mean AUC (SEM) ( $\mathrm{mm} \mathrm{Hg/5} \mathrm{min).}{ }^{\star} p<0.01 \mathrm{v}$ before study values, $\dagger p<0.05 \mathrm{v}$ before study values.

colonic tone from the onset of hyperventilation, increased colonic tone associated with hypocapnia during the immediate post-hyperventilation period, and the absence of change in colonic tone during eucapnic hyperventilation strongly suggest that the increase in colonic tone is a direct consequence of hypocapnia. The colonic effects of hypocapnia may either be peripherally or centrally mediated. Studies of vascular smooth muscle have shown that hypocapnia exerts both direct smooth muscle and neural effects resulting in smooth muscle relaxation. ${ }^{1-3}$ Thus, if vascular and colonic smooth muscle responded similarly to hypocapnia, a direct or peripheral effect of hypocapnia would be more likely to decrease rather than increase colonic tone, as shown in our study.

\section{Are the effects of hyperventilation neurally mediated?}

The timing of the increase in pulse rate is consistent with an initial vagal inhibition; however, decreased central parasympathetic outflow could not explain either the increased pulse interval variability as this would be expected to cause a decrease in pulse interval variability ${ }^{27}$ or the increase in colonic tone, as muscarinic cholinergic inhibition decreases colonic tone. ${ }^{18}$ The more plausible explanation is that the increases in pulse interval variability and

TABLE II Effect of eucapnic and hypocapnic hyperventilation on colonic tone and motility, end tidal $\mathrm{PCO}_{2}$, pulse rate, and pulse interval variability $(n=7$, mean (SEM))

\begin{tabular}{|c|c|c|c|c|}
\hline & \multicolumn{2}{|l|}{ Eucapnia } & \multicolumn{2}{|l|}{ Hypocapnia } \\
\hline & $H V T$ & Post-HVT & $H V T$ & Post-HVT \\
\hline \multicolumn{5}{|c|}{ Mean $\%$ change in tone relative to pre-HVT } \\
\hline Transverse colon & $2 \cdot 2(4 \cdot 4)$ & $-0 \cdot 8(4 \cdot 0)$ & $12 \cdot 8(3 \cdot 3)^{\star}$ & $10 \cdot 3(3 \cdot 8) \dagger$ \\
\hline Sigmoid colon & $2 \cdot 3(2 \cdot 4)$ & $0.8(1.4)$ & $6 \cdot 9(4 \cdot 1)^{\star}$ & $5 \cdot 2(2 \cdot 8)$ \\
\hline \multicolumn{5}{|c|}{ Mean change in phasic contractility relative to pre-HVT (AUC, $\mathrm{mm} \mathrm{Hg} / 5 \mathrm{~min}$ ) } \\
\hline Transverse colon & $-40(127)$ & $50(123)$ & $-53(129)$ & $100(111)$ \\
\hline Sigmoid colon & $334(300)$ & $331(294)$ & $522(150)^{\star}$ & $682(177)^{\star}$ \\
\hline End tidal $\mathrm{PCO}_{2}(\mathrm{~mm} \mathrm{Hg})$ & $38 \cdot 7(0 \cdot 9)$ & $38 \cdot 8(1 \cdot 1)$ & $21 \cdot 3(1 \cdot 0)^{\star}$ & $30 \cdot 0(1 \cdot 3)^{\star}$ \\
\hline $\begin{array}{l}\text { Pulse (bpm) } \\
\text { Coefficient of variation of }\end{array}$ & $69 \cdot 1(3 \cdot 4)^{\star}$ & $63 \cdot 7(3 \cdot 1)$ & $83 \cdot 0(2 \cdot 1)^{\star}$ & $65 \cdot 9(3 \cdot 7)$ \\
\hline interval $(\%)$ & $16 \cdot 6(3 \cdot 4)$ & $14 \cdot 1(2 \cdot 2)$ & $49.9(10 \cdot 8)^{\star}$ & $47 \cdot 4(11 \cdot 4)^{\star}$ \\
\hline
\end{tabular}

${ }^{\star} \mathrm{p}<0.025$ and $+0.025>\mathrm{p}<0.05$ compared with pre-eucapnic or hypocapnic hyperventilation by paired analyses. Abbreviations as in Table $\mathbf{I}$. colonic tone resulted from simultaneous decreases in both central sympathetic and parasympathetic outflow. The increase in phasic colonic contractility, which was only seen in the post-hyperventilation period may represent increased parasympathetic activity associated with the ensueing homeostatic responses, which are known to return the pulse rate to normal by increased cardiovagal tone.

\section{Do colonic responses to hyperventilation reflect} cardiovascular responses?

The activities and sensitivities of functional subsets of sympathetic neurones subserving vasomotor and motility functions are known to be under independent central control and have different propensities for respiratory modulation. ${ }^{23} 1213$ Indeed it has been suggested that respiration does not influence the activity of most motility regulating sympathetic neurones. 1213 This conclusion was based on studies using single and multi-unit nerve recordings in anaesthetised, paralysed, and artificially ventilated cats ${ }^{13}$ and may be of less direct relevance to the normal physiology pertaining in conscious humans. These species' differences may reflect the variation in experimental design such as the levels of hypocapnia and the potential interference with the response of the reticular activating system and higher centres by the anaesthesia in animal studies. None the less, such findings raise the intriguing possibility that changes in central sympathetic activity might evoke different effects on colonic and vascular smooth muscle. In contrast, we believe that as colonic tone is demonstrably increased by respiratory stimulation, it is more plausible that similar central neural responses activate changes in both cardiac and colonic function.

Additional evidence for the effects of hyperventilation on colonic tone is provided by studies of the role of hypocapnia in the mechanisms controlling hyperventilation induced cerebral vasoconstriction and changes in the electroencephalogram. ${ }^{4-6}$ In the absence of hypocapnia, hyperventilation in humans produces neither electroencephalogram nor cerebral circulatory changes. ${ }^{4}$ Furthermore, after selective alpha ${ }_{1}$ adrenergic receptor antagonism with thymoxamine or after disruption of cervical sympathetic innervation, as in tetraplegia, hyperventilation induced cerebral vasoconstriction is dramatically diminished, showing that an intact sympathetic nervous system is also essential in the normal response to hypocapnia. ${ }^{56}$ It seems possible therefore, that the increase in colonic tone is attributable to decreased central sympathetic outflow and involves sympathetic pathways in the reticular activating system, hypothalamic centres, and locus ceruleus, an effect that is critically dependent on the presence of hypocapnia and is potentially inhibited by anaesthetic agents used in experimental animals. Inhibition of sympathetic activity may increase colonic motility by a direct effect on myenteric neurones ${ }^{36}$ or indirectly, by modulating bulbospinal pathways thereby increasing sacral parasympathetic activity. ${ }^{37-39}$ 
In summary, we have shown that human colonic tone is increased by hypocapnic hyperventilation. Our findings differ from those of Maxton et al ${ }^{16}$ who studied the effect of hyperventilation on rectal motility in patients with IBS. Discrepancies in the two studies may reflect several differences in experimental design (bowel preparation, evaluation of sigmoid and transverse colon in our study) or the human subjects studied, and we need to pursue further studies in IBS. The similarity of regional colonic responses, however, and the timing of concomitant cardiovascular responses suggest that a central reduction in autonomic nervous control may be the significant factor, liberating the colon from the normal restraint of a centrally mediated 'sympathetic brake'. ${ }^{36}$ Our findings raise the possibility that hyperventilation in IBS patients may influence both colonic motor and sensory function. Thus, it may be hypothesised that increases in colonic tone lower the set point at which tension receptors within the colonic wall are stimulated and contribute to the heightened visceral perception in some patients with IBS. ${ }^{40-42}$ The methods established in this study allow us to directly test this hypothesis in patients with IBS in future studies and to evaluate the effect of the different levels of hypocapnia associated with hyperventilation in those patients.

We wish to thank Messrs Richard L Tucker and George $M$ Thomforde for technical support and Mrs Cindy Stanislav for secretarial assistance.

This study was supported in part by General Clinical Research Center grant no RR00585 from the National Institutes of Health. Dr Ford was supported by awards from the Wellington Foundation, Myre Sim Fund, and the Fulbright Commission.

1 Jung RC, Walsh JA, Hyman C. Response of human forearm muscle blood vessels to hyperventilation. Cardiovasc Res 1971; 5: 347-52.

2 Delius W, Hagbarth KE, Hongell A, Wallin BG. Manoeuvres affecting sympathetic outflow in human muscle nerves. Acta Physiol Scand 1972; 84: 82-94.

3 Vissing SF, Scherrer U, Victor RG. Stimulation of skin sympathetic nerve discharge by central command. Differential control of sympathetic outflow to skin and skeletal muscle during static exercise. Circ Res 1991; 69: 228-38.

4 Patel VM, Maulsby RL. How hyperventilation alters the electroencephalogram: a review of controversial viewpoints emphasizing neurophysiological mechanisms. points emphasizing neurophysiological

5 Corbett JL, Eidelman BH, Debarge O. Modification of central vasoconstriction with hyperventilation in normal man tral vasoconstriction with hyperventilatio
by thymoxamine. Lancet $1972 ;$ ii; 461-3.

6 Eidelman BH, Debarge O, Corbett JL, Frankel H. Absence of cerebral vasoconstriction with hyperventilation in tetraplegic man. Evidence for neurogenic control of cerebral circulation. Lancet 1972; ii: 457-60.

7 Gorman JM, Liebowitz MR, Fryer AJ, Stein J. A neuroanatomical hypothesis for panic disorder. $A m \dot{\mathcal{F}}$ Psychiatry 1989; 146: 148-61.

8 McKell TE, Sullivan AJ. The hyperventilation syndrome in gastroenterology. Gastroenterology 1947; 9: 6-18.

9 Chambers JB, Bland JM. Hyperventilation and irritable bowel syndrome. Lancet 1986; i: 221 .

10 Nyhlin H, Ford MJ, Eastwood J, Smith JH, Nicol EF, Elton RA, Eastwood MA. Non-alimentary aspects of the
irritable bowel syndrome. $\mathcal{F}$ Psychosom Res 1993; 37: irritable

11 Camilleri M, Neri M. Motility disorders and stress: significance to the irritable bowel syndrome. Dig Dis Sci 1989 ;
34: $1777-86$.

12 Janig W, McLachlan EM. Specialized functional pathways are the building blocks of the autonomic nervous system f Auton Nerv Syst 1992; 41: 3-14.

13 Boczek-Funcke A, Halber HJ, Janig W, Michaelis M Respiratory modulation of the activity in sympathetic neurones supplying muscle, skin, and pelvic organs in the cat. 7 Physiol 1992; 449: 333-61.

14 Valori RM, Cole E, Howard R, Cockel R. Hyperventilation (HV) increases the amplitude of esophageal contractions in healthy volunteers: a controlled study. Gut 1988; 29: A1447.

15 Danielopolu D, Savulesco A. Les effets de l'hyperventilation pulmonaire sur la motilite gastrique. $\mathcal{f}$ de Physiol et de Pathol Gener 1928; 16: 225-31.

16 Maxton DG, Prior A, Whorwell PJ. Effect of hyperventilation on distal colonic motility and rectal sensitivity in irritable bowel syndrome. Digestion 1991; 48: 70-4.

17 Camilleri M, Fealey RD. Idiopathic autonomic denervation in eight patients presenting with functional gastrointestinal disease. A causal association? Dig Dis Sci 1990; 35: 609-16.

18 Bharucha AE, Camilleri M, Low PA, Zinsmeister AR Autonomic dysfunction in gastrointestinal motility disorAutonomic dysfunction in gas
ders. Gut 1993; 34: 397-401.

19 Aggarwal A, Cutts TF, Abell TL, Cardoso S, Familoni B, Bremer J, et al. Predominant symptoms in irritable bowel syndrome correlate with specific autonomic nervous system abnormalities. Gastroenterology 1994; 106: 945-50.

20 Talley NJ, Phillips SF, Wiltgen CM, Zinsmeister AR, Melton LJ. Assessment of functional gastrointestinal disease: the bowel disease questionnaire. Mayo Clin Proc 1990; 65: 1456-79.

21 Zigmond A, Snaith R. The hospital anxiety depression scale. Acta Psychiatr Scand 1983; 67: 361-70.

22 Steadman CJ, Phillips SF, Camilleri M, Haddad AC Hanson RB. Variation of muscle tone in the human colon. Gastroenterology 1991; 101: 373-81.

23 von der Ohe MR, Hanson RB, Camilleri M. Comparison of simultaneous recordings of human colonic contractions by manometry and a barostat. Neurogastroenterology and Motility 1994; 6: 213-22.

24 Rosenthal RR. Simplified eucapnic voluntary hyperventilation challenge. $\mathcal{F}$ Allergy Clin Immunol 1984; 73: 676-9.

25 Vansteenkiste J, Rochette F, Demedts $M$. Diagnostic tests of hyperventilation syndrome. Eur Respir F 1991; 4: 393-9.

26 Phan CQ, Tremper KK, Lee SE, Barker SJ. Noninvasive monitoring of carbon dioxide: a comparison of the partial pressure of transcutaneous and end-tidal carbon dioxide with the partial pressure of arterial carbon dioxide. 7 Clin Monitoring 1987; 3: 149-54.

27 Ewing DJ, Dorsey DQ, Bellavere F, Clarke BF. Cardiac autonomic neuropathy in diabetes: comparison of measures of R-R interval variation. Diabetologia 1981; 21 : 18-24.

28 Goodwin GM, McCloskey DI, Mitchell JH. Cardiovascular and respiratory responses to changes in central command during isometric exercise at constant muscle tension. $f$ Physiol 1972; 226: 173-90.

29 Browse NL, Hardwick PJ. The deep breath-venoconstriction reflex. Clin Sci 1969; 37: 125-35.

30 Onrot J, Bernard GR, Biaggioni I, Hollister AS, Robertson D. Direct vasodilator effect of hyperventilation-induced hypocarbia in autonomic failure patients. $A m \mathcal{f} \mathrm{Med} \mathrm{Sci}$ 1991; 301: 305-9.

31 Baisset A, Cotonat J, Montastruc P. Influence de l'alcalose gazeuse hypocapnique sur les effets beta des sympathetiques. Path Biol (Paris) 1969; 17: 21-9.

32 Uvnas B. Cholinergic vasodilator nerves. Fed Proc 1967; 25: 1618-22.

33 Chauhan A, Mullins PA, Taylor G, Petch MC, Schofield PM. Effect of hyperventilation and mental stress on coronary blood flow in syndrome X. Br Heart 7 1993; 69: 516-24.

34 von der Ohe M, Camilleri M, Kvols LK, Thomforde GM. Motor dysfunction of the small bowel and colon in patients with the carcinoid syndrome and diarrhea. $N$ Engl patients with the carcinoid syn

35 von der Ohe $\mathbf{M}$, Hanson RB, Camilleri M. Serotonergic mediation of postprandial colonic tone and phasic responses in humans. Gut 1994; 35: 536-41.

36 Gillis RA, Dias Souza J, Hicks KA, Mangel AW, Pagani $\mathrm{FD}$, Hamilton BL, et al. Inhibitory control of proximal colonic motility by the sympathetic nervous system. $A m \mathcal{F}$ Physiol 1987; 253: G531-9.

37 Coote JH, Macleod VH. The influence of gulbospinal monoaminergic pathways on sympathetic nerve activity. f Physiol 1972; 224: 74-5.

38 Loewy AD. Forebrain nuclei involved in autonomic control. Prog Brain Res 1991; 87: 253-68.

39 Loewy AD. Descending pathways to sympathetic and parasympathetic preganglionic neurons. $\mathcal{f}$ Auton Nerv Syst 1981; 3: 265-75.

40 Ritchie J. Pain from distension of the pelvic colon by inflating a balloon in the irritable bowel syndrome. Gut 1973, 14: $125-32$.

41 Whitehead WE, Holtkotter B, Enck P, Hoelzl R, Holmes $\mathrm{KD}$, Anthony $\mathrm{J}$, et al. Tolerance for rectosigmoid distension in irritable bowel syndrome. Gastroenterology 1990; 98: 1187-92.

42 Cook IJ, Van Eeden A, Collins SM. Patients with irritable bowel syndrome have greater pain tolerance than normal subjects. Gastroenterology 1987; 93: 727-33. 